\title{
Natural Light and Productivity: Analyzing the Impacts of Daylighting on Students' and Workers' Health and Alertness
}

\author{
N. Shishegar, M. Boubekri
}

\begin{abstract}
Studies show that the quality of the school environment significantly influences students' academic performance. Among the many attributes of the school environment, light is one of the most visible and talked about ones. Lighting in the classrooms has been the subject of many studies for over a century. In recent years, special attention has been given to the impact of natural light on learning as light has physiological, psychological and behavioral influences on school children as well as workers. A multitude of surveys has indicated also that daylight impacts the health. We believe that workers' and students' health, satisfaction, attention, and consequently performance are improved with the help of natural light. This paper discusses the current literature and design-based evidence to evaluate the impacts of natural light on office workers and students' scholastic performance. Issues of timing and exposure to daylight are also discussed.
\end{abstract}

Keywords-Daylighting, Morning Sunlight, Students, Health, Workers Performance, Alertness

\section{INTRODUCTION}

Among the many elements that impact building occupants, lighting seems to have the most influence. Light is an essence for humans and it is known that has physical, physiological, and psychological influences [1].

In the early part of the $20^{\text {th }}$ century, natural light was the primary source of building illumination. In a short span of a couple of decades, electric lighting became the primary source of illumination, mostly because of convenience. In recent years, energy conservation and environmental concerns have changed those practices and brought daylighting once again at the forefront of the sustainability debate [2]. For decades, an appropriate lighting design was based on the idea that it should meet the needs of the building occupants especially in terms of visual task performance. However, recent connections between health and wellbeing and lighting have made lighting of building interiors one of the most salient environmental factors in architectural design [1]. Recent studies have proven that there is a correlation between lighting and humans' performance and health. Light does not only provide visual information but also constitutes a powerful modulator of our circadian rhythm and many non-visual functions including the state of alertness, mental focus, and cognitive performance [3].

F. N.Shishegar, Master of Architecture student at Illinois School of Architecture, University of Illinois at Urbana-Champaign, .

S. M. Boubekri, Associate professor at Illinois School of Architecture, University of Illinois at Urbana-Champaign, USA.
Light is also an important ingredient in educational settings, as it appears to have strong influences on cognition and learning. Research on electric lighting in classrooms has received some attention over the last few decades but research on the impact of natural light on students has been somewhat scarce [4]. The limited number of studies in this area seem to show that windows and daylight can enhance students' physical and psychological health, influence their mood, behavior and learning [5], [6]. Our study presents a comprehensive review of recent work that explored the relationship between daylight and students' and workers' health and performance. In this regard, the influence of morning sunlight on circadian system, brain activity and alertness of students are discussed.

\section{SPeCTRAl Characteristics OF DAYlighting AND ARTIFICIAL LIGHTING}

According to the Illuminating Engineering Society, "Daylighting refers to the art and practice of admitting beam sunlight, diffuse skylight, and reflected light from the exterior into a building to contribute to lighting requirements and energy saving through the use of electric lighting controls" [7].

Compared to natural light, artificial light provides a constant amount of light that can be turned on or off simply. Spectral quality is a complicated term which is used to show how warm or cool a light is and it is measured by two concept, namely the Correlated Color Temperature of light, (CCT) and Color Rendering Index (CRI). Generally, a high CRI of a light source translates to the color of an object appears close to the natural color seen under daylight or an indescant light sources of the same color temperature [8]. The sun generates a broad spectrum of light in order to provide sufficient wavelength for all people to recognize most colors. Therefore, it is considered that the light from the sun has a CRI of 100 which is the maximum value a light can achieve [9].

Various studies have demonstrated the multitude of benefits that daylight has in terms of its spectral qualities such as in the generation of Vitamin D through our skin. In fact, this is the nature of the light spectrum in the sunlight that makes it unique in the improvement of human health and it could not be found in electric lighting [8].

\section{DAYLIGHTING, HUMAN BODY, AND HEALTH}

Humans are affected both physically and psychologically by light. These effects are less quantifiable and consequently, the benefits of daylighting have been somewhat overlooked over 
the years. Physically, light affects our bodies in two ways: natural light interacts with our skin through photosynthesis and produces vitamin D. Vitamin D facilitates calcium absorption which strengthens our bones. Underexposure to sunlight causes vitamin D deficiency which can result in a range of illnesses. In the seventeenth century, vitamin D deficiency was attributed to rickets. Between 1910 and 1930, researchers determined that inadequate levels vitamin $\mathrm{D}$ cause abnormal bone frailty a consequence of insufficient calcium in bones [8], [10].

In a second way, light is able to affect our metabolism and our endocrinal and hormonal systems through our vision system [8]. Recent studies indicate that in addition to illuminating a space and providing visual comfort, natural light has also an important non-visual influence on our biological processes. Indeed, daylight is essential in synchronizing our circadian clock, which in turns is essential for stimulating blood circulation, influencing our metabolism, and controlling the levels of many of our hormones [11], [12].

For more than 150 years, scientists considered the rods and the cones to be the only photoreceptors in the eye. In 2002, a new stream in photobiology research - demonstrated that there is an alternative pathway from eyes to the brain. The new pathway regulates various interactions between biological functions and external luminous stimuli. A new type of photoreceptor in the retina of mammals was identified. This new photoreceptor, a specific subtype of retinal ganglion cells, describes the mechanism that light and darkness impact humans' biological systems [13].

Studies have also demonstrated that light influences health, well-being, alertness, and sleep quality. Natural light affects circadian rhythm, which is responsible for synchronizing human's body internal clock. Circadian rhythmicity in humans is responsible for many cognitive processes such as attention, executive functions and also memory. Generally, in cognitive performance, circadian rhythms are influential through a gradual enhancement during the biological day and a gradual decline in performance during the biological night [3]. Light is able to influence cognitive performance through its synchronizing /phase-shifting impacts on the circadian clock. As a result, exposure to natural light impacts brain cognitive performance.

The impact of building daylighting on sleep quality has been investigated in a limited number of studies. All of these studies show that the exposure to natural light improves the sleep quality of building occupants including office workers and students [14]-[16]. Friborg and colleagues examined the role of several self-regulatory variables such as mood, fatigue, behavioral habits, as well as psychological self-regulation as moderators of seasonality in sleep timing on 162 young participants in Norway. The results of this study indicate that not only sleep timing is delayed during the dark period (December) compared to seasons with brighter photoperiods (September and March), but also that seasonal sleep effects are followed by depression and, to a lesser extent, anxiety and fatigue. Inadequate exposure to daylight reduces the circadian cycle [16]. As a result, melatonin is secreted at the wrong times of the day causing chronic fatigue, depression, and possibly other illnesses [1], [17].

Moreover, lighting affects mood and attitude. Daylighting has been associated with improved mood, with an enhancement of morale, lower fatigue, and reduced eyestrain. The seasonal depression is considered as obvious evidence to prove the relationship between natural light and human endocrinal system. The seasonal depression, usually found among people living in northern latitudes, is referred to as Seasonal Affective Disorder (SAD) which describes the depression caused by lack of daylight [8]. According to Avery and colleagues, more than $10 \%$ of the population of Finland and about $6 \%$ of that of the United States suffer from this seasonal disorder [18].

Furthermore, many studies indicate that daylighting enhances mental performance and decreases aggressive behavior as well as depression [19]. Another advantage of daylighting is its variability in its intensity throughout the day and the seasons. In a research conducted by Hoffman and his colleagues on the impact of different lighting conditions on subjective mood in an experimental office showed that varying lighting levels have a potential advantage for office workers as far as their subjective mood [20]. Another important psychological aspect resulting from daylighting is meeting our need for contact with the outside world through daylight apertures in buildings [21]. In this regard, daylighting has a natural healing effect by its provisions of view to the outside world. Daylighting can enhance a connection to nature and directly improve the mood of the building occupants [22]. As shown in TABLE 1 there is a multitude of physiological and psychological benefits resulting from building daylighting.

TABLE I: NATURAL LIGHT AND HUMAN BODY

\begin{tabular}{c|c|c|c}
\hline \multicolumn{3}{c}{ Natural light and human body } \\
\hline \multicolumn{2}{c}{ Physically } & \multicolumn{2}{c}{ Psychologically } \\
\hline Improve & Decrease & Improve & Decrease \\
\hline Vitamin D & $\begin{array}{c}\text { Cancer } \\
\text { Possibility }\end{array}$ & Mood & Depression \\
\hline Visual System & $\begin{array}{c}\text { Abnormal Bone } \\
\text { Formation }\end{array}$ & $\begin{array}{c}\text { Mental } \\
\text { Performance }\end{array}$ & Stress \\
\hline $\begin{array}{c}\text { Circadian } \\
\text { Rhythms }\end{array}$ & - & Alertness & Sadness \\
\hline Sleep Quality & - & Brain activity & Violent Behavior \\
\hline \hline
\end{tabular}

\section{DAYLIGHTING AND PRODUCTIVITY}

Many studies have attempted to correlate daylighting to an improved productivity at the workplace. Boyce et al. defined the productivity of an individual, or an organization, as the ability to improve work production by increasing in either quantity and/or quality of the product or service to be delivered [23]. According to these authors, there are three routes by which lighting conditions can affect the performance of individuals: (1) visual system, (2) circadian system, (3) and perceptual system. Lighting conditions determine the capabilities of the visual system. As mentioned in previous paragraphs, the circadian system is also influenced by light/dark cycle which is related to lighting conditions directly [23]. Fig. 1 shows a conceptual framework for considering the 
relationship between lighting conditions and human performance through the visual system, circadian system and perceptual system [23].

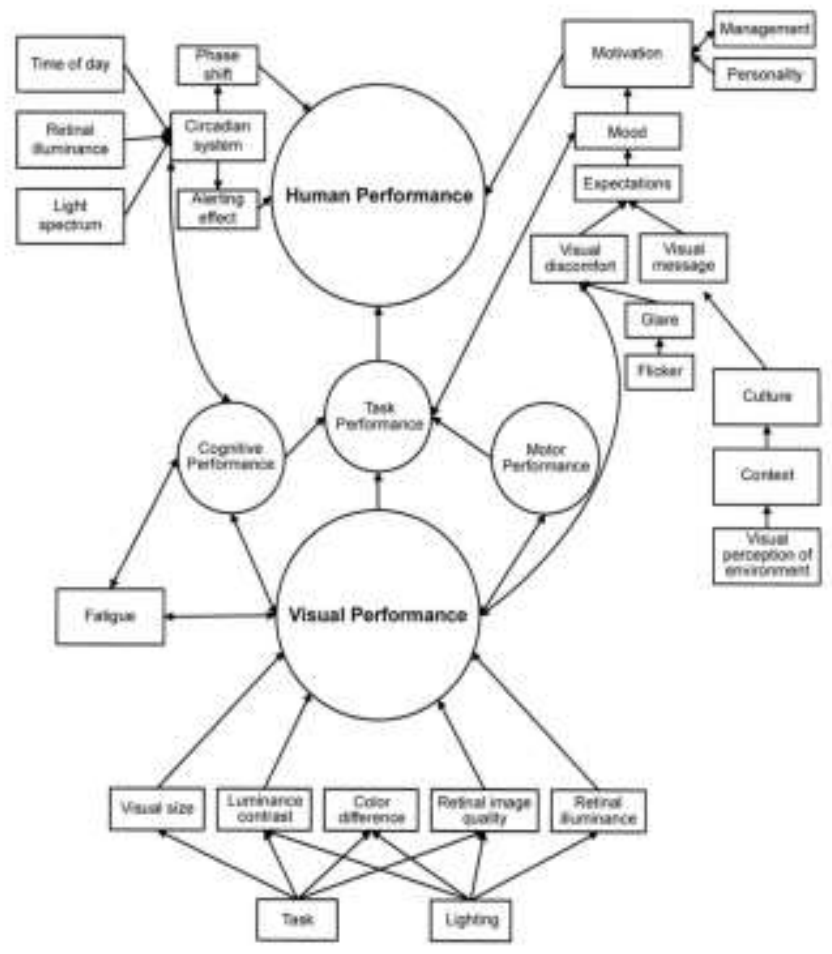

Fig. 1. A conceptual framework setting out the routs by which lighting can influence human performance. The arrows indicate the direction of the effects [23]

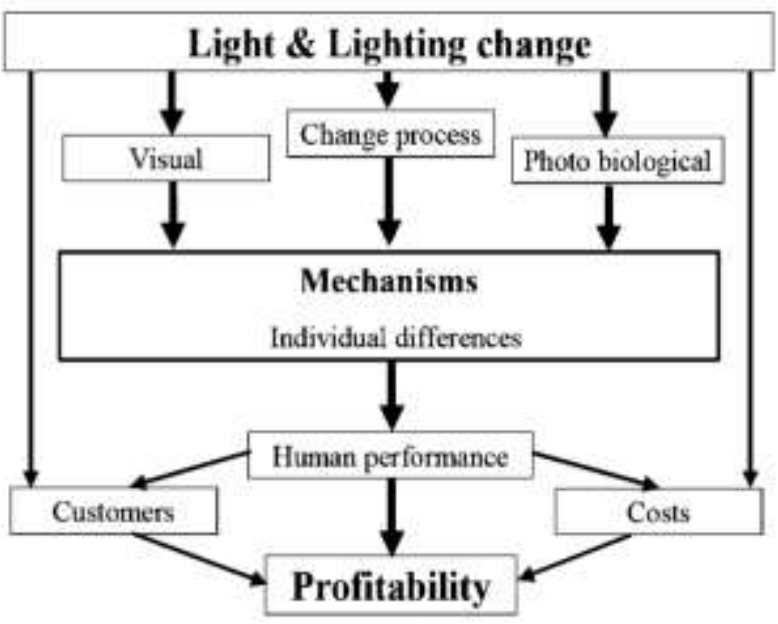

Fig.2. Model of the impacts of light and lighting change on profitability in the industrial environment [24].

Just and Tenner, present another conceptual model of the influence of light and lighting condition changes on productivity in the industrial environment [24]. This model is shown in Fig. 2. The perspective behind this model is different from that stated by Boyce et al. According to this study, installing new lighting in the work environment affects the performance of workers through several mechanisms. There are at least 10 mechanisms that contribute to the enhancement of people's productivity including visual performance, visual comfort, visual ambiance, interpersonal relationships, biological clock, stimulation, job satisfaction, problem-solving, the halo effect, and variability and changes in the environment [24].

Other studies have evaluated the impact of natural light on workers' productivity from other points of view such as health, well-being, physical activity, motivation, achievements, and etc. In the following paragraphs, some of those studies will be introduced.

Studies on the impacts of light on humans' productivity date back to 1920s. One of these early studies examined the impact of lighting quality on silk weavers. In this study, Tennesen and Cimprick [2] found out that people with views of natural vegetation posed more attention during the work hours. The view from windows is not the only important part of daylighting techniques. Natural light increases attention and alertness during the post-lunch dip and was shown to be helpful in increasing alertness for mundane and repetitive tasks [21].

Another study conducted in the early 1990s showed that employees of West Bend Mutual Insurance Company who moved into a new building and who were provided with personal control over their workstation environmental attributes such as temperature, task lighting registered higher performance overall compared to before the move. By moving to a new building, the number of employees having a workstation with a window view increased from $30 \%$ to $96 \%$. West Bend determined that compared to the old building, the employees had a $16 \%$ increase in claims processing productivity in the new building [19], [25].

Borisuit and colleagues evaluated the effects of daylighting on office workers' performance from the perspective of visual comfort, alertness, and mood. Their study was conducted on twenty-five young subjects who spent two afternoons either under electric lighting or daylighting conditions with skylights only and without a view to the exterior. They found significantly higher visual acceptance scores under daylight than electric light, despite the lack of direct outside views. While subjective alertness and physical well-being decreased for both lighting conditions in the course of the afternoon, subjects felt sleepy earlier under electric lighting than daylighting. Physical well-being became worse in the course of the afternoon under electric lighting only. Higher visual comfort, alertness, and well-being can be one of the indicators of office workers work satisfaction and all of these factors enhance productivity as a result [26].

In another study, Boubekri and colleagues examined the impact of daylight exposure on office workers' productivity by considering subjective health, well-being, physical activity and sleep quality, all factors that have a significant influence on the productivity of individuals. Results of this study indicate that office workers in offices without windows reported poorer scores with respect to vitality, physical activity and sleep quality in comparison to the group with windows [14]. This same study revealed that office workers with plenty of daylight throughout the day sleep on average 46 minutes longer than 
their counterparts with no daylight and windows. Other studies focused on absenteeism as a gauge to measure productivity [27].

The fact that daylight seems to influence productivity in the office setting could be extrapolated to the classroom environment as well and one $m$ ay hypothesize that daylighting influences students' academic performance.

\section{NATURAL LIGHT AND STUDENTS’ ACADEMIC PERFORMANCE}

The main purpose in the architectural design of schools is to promote learning as well as optimize physical and emotional health. It should be noted that schools are among the most crowded buildings and host young people. Applying adequate daylighting techniques into the architecture of a school contributes the occupants' physical and emotional health [28].

Students and teachers can benefit from integrating and managing daylight properly. Saving energy, high student attendance, good health and strong academic performance, and a less stress for students are only a few benefits of adequate daylighting in educational environments [19]. Studies show that teachers are happier when they have the ability to control their environment. Healthy and happy teachers save schools money and perform better in teaching [29]. In contrast, a school with inadequate lighting design might demote students' ability of learning. Poor light spectral quality in the classroom can create a strain on students' eyes, lead to a decrease in information processing and in learning ability and may cause higher stress levels in students [30].

Kuller and Lindsten studied children's health and behavior in classrooms with and without windows for an entire academic year. They concluded that work in classrooms without windows affected the basic pattern of the hormone cortisol, which is related to stress, and could, therefore, have a negative effect on children's health and concentration. However, no direct relationship was found between cortisol levels and student performance and health [5], [28], [31]. Another study in Sweden showed that observed behavior and circadian hormone levels of elementary students in classrooms with natural light stayed closer to expected norms in comparison with students in classrooms with only fluorescent lighting [32].

Heschong and Mahone studied the impact of natural light and students and found that the addition of natural light improves student test scores by up to $20 \%$ [32]. Taylor states that students in classrooms with the most daylighting progress $20 \%$ and $26 \%$ faster in one year in math and reading tests respectively, compared to their counterparts in classrooms with little or no daylight [33]. Another study conducted by Kim et al. on daylight quality of educational facilities in South Korea shows that daylight had an influence on the quality of the educational environment, and students' learning performance [34].

Aggio et al. [35] evaluated the impact of light exposure on the productivity of 229 students from the perspective of physical activity and sedentary time (age mean $=8.8$ years) in Camden, UK. To investigate it, daily sedentary time, Moderate and Vigorous Physical Activity (MVPA) and light exposure were measured daily by using a tri-axial accelerometer with an ambient light sensor during the summer. Their results indicate the existence of significant associations between average daily light exposure and sedentary time and in MVPA. Researchers concluded that average light exposure is positively associated with time in MVPA and negatively associated with sedentary time. Therefore, one may conclude that increasing daylight exposure might be a useful intervention strategy for promoting physical activity and consequently vitality and performance among young Students [35].

Just like absenteeism in the work environment, attendance is another factor which could be considered a measure of students' performance. Schools that have integrated full spectrum fluorescent lights or natural light witness an increase in student and teacher attendance when compared to traditionally lit schools with lesser quality fluorescent light fixtures. A study of the full spectrum fluorescent Canadian schools reported that students had an attendance increase of 3.2 to 3.8 more days per year than students in traditional fluorescent lighting schools [19]. Durant Road Middle School in Wake County school system in North Carolina was specially designed to incorporate daylighting in its classrooms. It reported the best health and attendance in the entire school system and an attendance rate higher than $98 \%$. The school also claimed the lowest number of faculty health absences in the area [19].

\section{IMPACT OF MORNING BRIGHT LIGHT ON ALERTNESS AND PERFORMANCE}

It should be considered that different spectrums of sunlight have various impacts on humans' body and particularly eyes. In fact, visual and non-visual effects of light on brain functions and responses are dependent on the specific wavelength of the light received through the eye. As a result, morning sunlight with a short wavelength spectrum influences people's body differently compared to the long wavelength of afternoon sunlight. It was observed that 6.5 hours exposure to blue light (460-nm monochromatic light) during the biological night decreases subjective sleepiness and enhances auditory performance and alertness compared with exposure to an equal photon density of green light (555-nm monochromic light) [36]. These findings show that the alerting impacts of ocular light exposure are wavelength dependent and there is a greater sensitivity to short wavelengths in the visible spectrum. It was also observed that even a few tens of seconds of light exposure brings about immediate and significant wavelength-dependent changes in the brain [39]. According to Vandewalle, 50 seconds exposure to blue light increases activity in the left hippocampus, left thalamus, and right amygdala, as compared to green light [37].

Morning light plays an essential role in the synchronization of metabolic rhythms to the $24 \mathrm{~h}$ rotational cycle of the Earth. Without regular daylight entrainment, the human circadian clock would run on average on a $24 \mathrm{~h}$ and 15-30 minutes cycle, ultimately leading to a shift of the circadian pacemaker, and a desynchronisation of our biological clock. The impact of early morning sunlight on students' circadian system has been investigated by Figueiro and Rea [38, 39] in the outside 
laboratory conditions. This study showed that lack of short-wavelength light in the morning brings about 30 minutes delay in circadian phase for $8^{\text {th }}$-grade students. Other studies showed similar results under controlled laboratory conditions. The findings of the controlled laboratory results confirm those found in real settings of school environments. Circadian rhythm is largely responsible for numerous cognitive processes such as attention, alertness, sleep quality, mood, as well as memory. These are key ingredients in the learning processes. Exposure to natural light in the classrooms seems to be essential in improving students learning.

The impact of morning exposure to daylight was also examined by Keis et al. [40]. The results of this study prove that the blue-enriched white light seems to have an effect on basic information processing among high-school students. Blue light appears to improve processing speed and concentration of students compared to standard lighting. Furthermore, a recent study showed that one hour of exposure to morning bright white light advances sleep and wake-up parameters and affects cognitive performance and alertness [41]. These studies suggest that a sufficiently applied light intervention could enhance alertness, and thus performance, at work significantly. Other recent studies showed the effects of bright light on healthy-active persons during regular daytime working hours. A field study by Smolders, De Kort, and Van den Berg [42] provided further evidence for a direct link between exposure to more intense light and feelings of vitality during daytime and in everyday situations. Their results showed that hourly light exposure was a significant predictor of vitality. People who were exposed to more light experienced higher feelings of vitality, over and above the variance explained by person characteristics, time of day and activity patterns. Another laboratory study showed that even in the absence of sleep and light deprivation, exposure to a higher illuminance at eye level can induce subjective alertness and vitality, increase physiological arousal and improve performance on a sustained attention task [44]. The same results were found by Leichfried et al. who concluded that that early morning illumination improves subjective alertness and mood, but had no impact melatonin level and mental performance of individuals [43].

Short exposure to light has been found to improve thalamic, frontal, and parietal activities, and thus affects fatigue [38], [44]. Moreover, as short-wavelength light is significantly effective for phase-shifting the circadian pacemaker, suppressing melatonin, and activating the autonomic nervous system, studies suggest that long duration exposure of bright light is an influential potential countermeasure for fatigue, especially during the biological night. Routine tasks such as driving which need sustain attention are improved by exposure to bright light [38]. It can also positively affect cognitive as well as physical performance in healthy individuals [45]-[47].

All these studies demonstrate a direct relationship between intense early morning daylight and alertness, vitality, and cognitive performance. All of these are key factors affecting work and scholastic performance of individuals. Although these studies have not assessed the impacts of morning daylight on students' alertness and productivity directly, they might be extended to students. Considering the results of these studies, it appears to be necessary to expose students to short bright light during the early part of the day to maintain entrainment. These findings seem to have significant and practical implications for the design of schools in general and classrooms in particular. Impacts of blue light in schools could be considered as a simple, beneficial, non-pharmacological way which enhances students' health, alertness, brain activity, and vitality and perhaps academic performance. Sunlight seems to be the most appropriate lighting source in schools as it can deliver the adequate quantity and spectrum as well as the proper timing and duration of light exposure [38], [39]. These findings should have direct implications on the layout of schools as well as façade orientations and fenestration design in schools

\section{CONCLUSIONS}

Among the many elements in the indoor environment, lighting seems to have the most impacts on the human body. Various studies have investigated the impacts of light on people from different points of view for over a century. These studies demonstrate that light has visual and non-visual influences on people. Among different source of lighting, it seems that sunlight is the most crucial one and cannot be easily replaced by electric light because of its dynamic quality as well as spectral features. In addition, it is the most important source of vitamin $\mathrm{D}$ which is necessary for the strength of human bones and overall health. In addition to its role as an agent for vitamin D production, natural light can improve subjective mood, attention, cognitive performance, physical activity, sleep quality, and alertness in students and workers. All these factors could be considered key aspects for optimal academic and work performance.

\section{REFERENCES}

[1] L. Bellia, F. Bisegna, and G. Spada, "Lighting indoor environment: visual and non-visual light sources with different spectral power distribution," Building and Environment, vol. 46, pp. 1984-1992, 2011. http://dx.doi.org/10.1016/j.buildenv.2011.04.007

[2] J.H. Heerwagen, "Green buildings, organizational success, and occupant productivity," Building Research and Information, vol. 28 (5), pp. 353-367, 2000.

http://dx.doi.org/10.1080/096132100418500

[3] G. Vandewalle, P. Maquet, and D.J. Dijk, "Light as a modulator of cognitive brain function," Trends in Cognitive Sciences, vol. 13, pp. 429-438, 2009.

http://dx.doi.org/10.1016/j.tics.2009.07.004

[4] L. Baker, A History of School Design and Its Indoor Environmental Standards, 1900 to Today. Washington, DC: National Clearinghouse for Educational Facilities, 2011, pp. 39-45.

[5] R. Kuller, C. Lindsten, "Health and behavior of children in classrooms with and without windows. Journal of Environmental Psychology, vol. 12, pp. 305-17, 1992. http://dx.doi.org/10.1016/S0272-4944(05)80079-9

[6] Heschong Mahone Group. Windows and Classrooms: A Study Of Student Per-Formance And The Indoor Environment. Sacramento, CA: California Energy Commission; 2003.

[7] IES RP-5-13. Recommended Practice for Daylighting Buildings. Illuminating Engineering Society, 2013.

[8] Boubekri, M. Daylighting, Architecture and Health, NY: Architectural Press, 2008.

[9] F. Sharp, D. Lindsey, J. Dols, J. Coker, "The use and environmental impact of daylighting," Journal of Cleaner Production, vol. 85, pp. 462-471, 2014. 
http://dx.doi.org/10.1016/j.jclepro.2014.03.092

[10] V.R. Garcia-Hansen, "Innovative daylighting systems for deep-plan commercial buildings." PhD. Dissertation, Faculty of Built Environment and Engineering, Queensland University of Technology, Brisbane, 2006.

[11] S. Altomonte, "Daylight and the Occupant, Visual and physio-psychological well-being in built environment," presented at $26^{\text {th }}$ Conference on Passive and Low Energy Architecture, Quebec City, Canada, 22-24 June 2009.

[12] W.J.M. Van [14], "Non-visual biological effect of lighting and the practical meaning for lighting for work" Applied Ergonomics, vol. 37, pp. 461-466, 2006 http://dx.doi.org/10.1016/j.apergo.2006.04.009

[13] W.J.M. Van Bommel, G.J. Van den Beld, "Lighting for work: a review of visual and biological effects," Lighting Research and Technology, vol. 36 (4), pp. 255-269, 2004. http://dx.doi.org/10.1191/1365782804li122oa

[14] M. Boubekri, L. Cheung, K. Reid, C. Wang, \&and P. Zee, "Impact of windows and daylight exposure on overall health and sleep quality of office workers: A case- control pilot study," Journal of Clinical Sleep Medicine, vol. 10(6), pp. 603-611, 2014. http://dx.doi.org/10.5664/jcsm.3780

[15] D. Aggio, L. Smith, A. Fisher, and M. Hamer, "Association of light exposure on physical activity and sedentary time in young people," International Journal of Environmental Research and Public Health, vol. 12, p. 2941-2949, 2015. http://dx.doi.org/10.3390/ijerph120302941

[16] O. Friborg, J. Rosenvinge, R. Wynn, and M. Gradisar, "sleep timing, phonotype, mood, and behavior at an arctic latitude $\left(69^{\circ} \mathrm{N}\right)$. Sleep Medicine, vol. 15, pp. 798-807, 2014. http://dx.doi.org/10.1016/j.sleep.2014.03.014

[17] R.G. Stevens, and M.S. Rea, M. S., "Light in the built environment: potential role of circadian disruption in endocrine disruption and breast cancer," Cancer causes and control, vol.12, pp. 279-287, 2011. http://dx.doi.org/10.1023/A:1011237000609

[18] D.H. Avery, D.N Eder, M.A. Bolte, C.J. Hellekson, D.L. Dunner, M.V. Vitiello, and P.N. Prinz, "Dawn simulation and bright light in the treatment of SAD: a controlled study," Biological Psychiatry, vol. 50(3), pp. 205-16, 2001. http://dx.doi.org/10.1016/S0006-3223(01)01200-8

[19] L. Edwards, P. A. Torcellini, and N. R. E, "A literature review of the effects of natural light on building occupants," National Renewable Energy Laboratory, 2002.

[20] G. Hoffmann, V. Gufler, A. Griesmacher, C. Bartenbach, M. Canazei, S. Staggl, and M. Schobersberger, "Effects of Variable Lighting Intensities and Color Temperatures on Sulphatoxymelatonin and Subjective Mood doi:10.1016/j.apergo.2007.11.005.

[21] C.L. Robbins, Daylighting: Design and Analysis, New York: Van Nostrand Reinhold, 1986

[22] L. Gelfand, E. C. Freed, Sustainable School Architecture: Design for Elementary and Secondary School, John Wiley and Sons Inc.

[23] P. Boyce, C. Hunter, and O. Howlett, "The Benefits of Daylight through Windows," Lighting Research Center, Rensselaer Polytechnic Institute, New York, 2003.

[24] H. Jusle, and A. Tenner, "Mechanisms involved in enhancing human performance by changing the lighting in the industrial workplace," International Journal of Industrial Ergonomics, vol. 35, pp. 843-855, 2005. http://dx.doi.org/10.1016/j.ergon.2005.03.002

[25] J.J. Romm and W.D. Browning, "Greening the building and the bottom line - Increasing productivity through energy-efficient design," Rocky Mountain Institute, 1994.

[26] A. Borisuit, F. Linhart, J. Scartexxini, and M. Munch, "Effects of realistic office daylighting and electric lighting conditions on visual comfort, alertness and mood, lighting Res," Technol., [Online], vol. 0, pp. 1-18. Available: lrt.sagepub.com

[27] S. Markussen, and K. Røed, "Daylight and absenteeism - Evidence from Norway," Economics and Human Biology, vol. 16, pp. 73-80, 2014. 1-s2.0-S1570677X14000252-main.

[28] A. Demir, "Impact of daylight on student and teacher performance, Journal of Educational and Instructional Studies in the World, vol. 3 (1), pp. 1-7, 2013.

[29] Johnson, Raymond, J. Leo, M. Bernabei, "Green Building Design for Schools: The Next Time Around," Strategic Planning for Energy and the Environment, vol. 26 (2), pp. 56-77, 2006. http://dx.doi.org/10.1080/10485230609509711
[30] M. Anselm Dass, N. Ibrahim, N. Lukman, "Evaluation of daylighting at public school classrooms in Ipoh, Perak," Alam Cipta, vol. 7(1), pp. 27-34, 2014.

[31] National Research Institute (National Research Council), Green Schools: Attributes for Health and Learning, Washington: The National Academies Press, 2007.

[32] L. Heschong, L. Roger, S. Wright, "Daylighting impacts on human performance in school. Journal of Illuminating Engineering Society Summer, 101-114, 2002.

[33] A. Taylor and K. Engass, Linking Architecture and Education: Sustainable Design For Learning Environments, China: University of New Mexico Press, 2009.

[34] T. Kim, W. Hong, H. Kim, "Daylight evaluation for educational facilities established in high-rise housing complexes in Daegu, South Korea," Building and Environment, vol. 78, pp. 37-144, 2014, http://dx.doi.org/10.1016/j.buildenv.2014.04.026

[35] D. Aggio, L. Smith, A. Fisher, and M. Hamer, "Association of Light Exposure on Physical Activity and Sedentary Time in Young People," International Journal of Environmental Research and Public Health, vol. 12, pp. 2941-2949, 2015. http://dx.doi.org/10.3390/ijerph120302941

[36] S.W. Lockley et al. "Short-wavelength sensitivity for the direct effects of light on alertness, vigilance, and the waking electroencephalogram in humans," Sleep Physiology, vol. 29, pp. 161-168, 2006.

[37] G. Vandewalle, "Brain responses to violet, blue, and green monochromatic light exposures in humans: prominent role of blue light and the brainstem," PLOS ONE, vol. 2, pp. 1239-1247, 2007. http://dx.doi.org/10.1371/journal.pone.0001247

[38] M.G. Figueiro and M.S. Rea, "Evening daylight may cause adolescents to sleep less in spring than in winter," Chronobiology International, vol. 27, pp. 1242-1258, 2010a. http://dx.doi.org/10.3109/07420528.2010.487965

[39] M.G. Figueiro, M.S. Rea, "Lack of short-wavelength light during school day delays dim light melatonin onset (DLMO) in middle school students," Neuroendocrinology Letters, vol. 31, pp. 92-96, 2010 b.

[40] O. Keis, H. Helbig, J. Streb, K. Hille, "Influence of blue-enriched classroom lighting on students' cognitive performance," Trends in Neuroscience and Education, vol. 3, pp. 86-92, 2014.

http://dx.doi.org/10.1016/j.tine.2014.09.001

[41] R.W. Corbett, B. Middleton, J. Arendt, "An hour of bright white light in the early morning improves performance and advances sleep and circadian phase during the Antarctic winter," Neurocience Letters, vol. 525(2), pp. 146-151, 2012 http://dx.doi.org/10.1016/j.neulet.2012.06.046

[42] K.C. Smolders, Y.A. De Kort, A.D. Tenner and F.G. Kaiser, "Need for recovery in offices: Behavior-based assessment," Journal of Environmental Psychology, vol. 32, pp. 126-134, 2012. http://dx.doi.org/10.1016/j.jenvp.2011.12.003.

[43] V. Leichtfred et al. "Intense illumination in the morning hours improved mood and alertness but not mental performance," Applied Ergonomics, vol. 46, pp. 54-59, 2015. http://dx.doi.org/10.1016/j.apergo.2014.07.001

[44] G. Vandewall, et al., "Daytime light exposure dynamically enhances brain responses," Curr Biol, vol. 16(16), pp.1616-21, 2006 http://dx.doi.org/10.1016/j.cub.2006.06.031

[45] T. Kantermann, S. Forstner, M. Halle, L. Schlangen, T. Roenneberg, A. Schmidt- Trucksass, "The stimulating effect of bright light on physical performance depends on internal time," PLoS ONE, vol. 7 (7), pp. 406-55, 2012 http://dx.doi.org/10.1371/journal.pone.0040655

[46] A.B. Dollins, H.J. Lynch, R.J. Wurtman, M.H. Deng, K.U. Kischka,, R.E. Gleason, H.R. Lieberman, "Effect of pharmacological daytime doses of melatonin on human mood and performance," Psychopharmacology (Berl.), vol. 112 (4), pp. 490-496, 1993. http://dx.doi.org/10.1007/BF02244899

[47] F.A. Fraschini, D. Cesarani, D. Alpini, D. Esposti, B.M. Stankov, Melatonin influences human balance," Biol. Signals Recept. Vol. 8 (1-2), pp. 111-119, 1999.

http://dx.doi.org/10.1159/000014578 